\title{
PARTIÇÃO DE SUBSTÂNCIAS HÚMICAS EM SOLOS BRASILEIROS $^{(1)}$
}

\author{
Lauana Lopes dos Santos ${ }^{(2)}$, Julian Junio Jesus Lacerda ${ }^{(3)} \&$ Yuri Lopes Zinn ${ }^{(4)}$
}

\section{RESUMO}

As substâncias húmicas (SH) representam o principal reservatório de carbono orgânico total do solo (COT) e sua partição entre diferentes frações de solubilidade em meio alcalino ou ácido pode guardar relação com o tipo de solo e manejo adotado. O objetivo deste trabalho foi comparar a partição das SHs, de acordo com profundidade, tipo de solo, bioma e uso do solo no Brasil. Revisou-se a literatura, incluindo teses, dissertações, artigos e resumos em anais de eventos, em busca de dados sobre o teor de COT, sua porcentagem como ácidos húmicos (AH), ácidos fúlvicos (AF) e humina (HU) e a razão AH/AF. Os dados foram estratificados por intervalos comparáveis de profundidades $(0-5,5-10,0-20$, 20-50, 50-100 e >100 cm), biomas (Mata Atlântica, Cerrado, Amazônia, Pampa e Caatinga), ordem de solo (Argissolo, Latossolo, Cambissolo, Planossolo, Neossolo, Gleissolo e Organossolo) e principais usos do solo (florestas nativas, pastagem natural, pastagem plantada, eucalipto, culturas perenes e anuais). Os dados foram analisados por estatística descritiva, correlações de Spearman e análise de componentes principais (ACP). Nos Argissolos, Latossolos e Organossolos, a fração HU contribuiu com metade do COT, tendendo a diminuir em profundidade. Para Latossolos e Organossolos, a fração AF tendeu a aumentar em profundidade. Em Neossolos, a fração AH aumentou em profundidade, embora tenha diminuído em Gleissolos e Planossolos. A razão AH/AF geralmente diminui em profundidade. Pela ACP, não foi possível identificar um padrão de agrupamento das amostras em razão do tipo de bioma e uso do solo, sugerindo que a partição das SHs tem baixo potencial como indicador de efeitos do manejo ou condições ambientais, embora seja útil para discriminar processos de humificação em algumas ordens de solo.

Termos de indexação: humina, ácido húmico, ácido fúlvico, bioma, uso da terra, análise de componentes principais.

(1) Recebido para publicação em 15 de junho de 2012 e aprovado em 26 de abril de 2013.

(2) Mestranda, Programa de Graduação em Ciência do Solo, Universidade Federal de Lavras - PPGCS/UFLA. Caixa Postal 37. CEP 37200.000 Lavras (MG). Bolsista CNPq. E-mail: lauanasantos@ymail.com

(3) Doutorando, PPGCS/UFLA. Bolsista FAPEMIG. E-mail: julianlacerda@gmail.com

(4) Professor, Departamento de Ciência do Solo, UFLA. E-mail: ylzinn@dcs.ufla.br 


\title{
SUMMARY: PARTITIONING OF HUMIC SUBSTANCES IN BRAZILIAN SOILS
}

\begin{abstract}
Humic substances (HS) are the main pool of total soil organic carbon (TOC). They are partitioned in different fractions according to its solubility in alkali or acid medium, which can be related to soil type and management. This work aimed to compare HS partitioning in Brazilian soils according to soil depth, soil type, biome, and land uses. In a literature review of theses, dissertations, journal articles, and abstracts in proceedings, quantitative data on TOC partitioning in humic acids (HA), fulvic acids (FA), and humin (HU), as well as the HA / FA ratio were compiled. The data were sorted according to comparable depths (0-5, 5-10, 0-20, 2050, 50-100, and $>100 \mathrm{~cm}$ ), biomes (Atlantic rainforest, Cerrado savanna, Amazon rainforest, southern prairies, and Caatinga scrubland), soil order (Ultisols, Oxisols, Inceptisols, Entisols, Histosols and soils with aquic moisture regimes), and land use systems (native forests, prairies, pastures, eucalypt, and annual or perennial crops). Data were analyzed by descriptive statistics, Spearman correlation, and principal component analysis (PCA). In Ultisols, Oxisols, and Histosols, humin accounted for at least half of TOC and tended to decrease with depth. In Oxisols and Histosols, FA tended to increase in depth. In the Entisols, HA increased with depth, but decreased in Histosols and some Ultisols. Generally, the HA / FA decreased in the deeper layers. Results of PCA indicated no effect of biomes and land use systems on the quantitative partitioning of HS, suggesting its low potential as indicator of management effects or environmental conditions, although useful to discriminate humification processes in some soil taxa.
\end{abstract}

Index terms: humin, humic acids, fulvic acids, biome, land use systems, principal component analysis.

\section{INTRODUÇÃO}

A transformação contínua de resíduos orgânicos no solo leva à formação de um complexo de substâncias de elevado grau de alteração, denominado substâncias húmicas (SH). Com base em sua solubilidade em meio aquoso, as substâncias húmicas são classicamente divididas em três categorias: ácidos fúlvicos (AF), solúveis em $\mathrm{pH}$ ácido ou alcalino; ácidos húmicos $(\mathrm{AH})$, solúveis em $\mathrm{pH}$ alcalino; e humina (HU), insolúvel em qualquer $\mathrm{pH}$. Tradicionalmente, admite-se que esses compostos variam em peso molecular na ordem crescente $\mathrm{AF}<\mathrm{AH}<\mathrm{HU}$ (Zech et al., 1997; Hayes, 1998) e que cerca de $80 \%$ do carbono orgânico do solo está contido nas SHs, em especial na HU (Guerra \& Santos, 1999). As SHs têm capacidade de interagir com argilas e alterar as propriedades físicas, químicas e biológicas do solo, exercendo papel importante na fertilidade e estrutura do solo, além de imobilizar metais pesados e pesticidas e atuar como fatores de crescimento de brotos e raízes (Bayer \& Mielniczuk, 1999).

O estudo das SHs foi iniciado com sua extração de turfas em 1786, por Achard, na Alemanha; em 1797, Vauquelin tentou o mesmo em resíduos de plantas. $\mathrm{O}$ termo "húmus", proveniente do latim e equivalente a "solo", foi introduzido por Saussure em 1804 para descrever o material orgânico de coloração escura originado do solo. Entre 1826 e 1837, Sprenge buscou compreender a origem e a natureza química das SHs. Berzelius deu contribuições valiosas sobre métodos de extração e conteúdo elementar das SHs (Rocha \& Rosa, 2003); em 1919, Oden cunhou a nomenclatura de AF, AH e HU usada até hoje. Em 1960, foi obtido o primeiro espectro de ressonância magnética nuclear de AH. A maioria dos trabalhos já realizados sobre $\mathrm{SH}$ referese a solos de países de clima temperado. No Brasil, Volkoff \& Cerri (1980) estudaram a química das SHs e sua relação com o ambiente, usando técnicas isotópicas e espectroscópicas. No entanto, em razão do considerável custo e tempo despendido nessas análises qualitativas, atualmente a maioria dos trabalhos sobre SH no Brasil é embasada na quantificação das diferentes frações húmicas e suas proporções como indicadoras de condições ambientais ou alterações por causa do manejo do solo (Lima, 2001; Leite et al., 2003; Cunha et al., 2007). Alguns autores (Valladares et al., 2003; Fontana et al., 2008; Ebeling et al., 2011) inclusive acreditam que a proporção relativa dessas frações pode ser utilizada como atributo para classificação de solos. Apesar desses e muitos outros trabalhos sobre a partição quantitativa das SHs, ainda não há um levantamento sistemático da literatura, embasado por análise estatística abrangente, que permita inferir sobre a validade do uso dessa informação para a compreensão de processos edáficos no Brasil.

Embora estudos recentes tenham questionado a natureza das clássicas frações $\mathrm{AH}, \mathrm{AF}$ e $\mathrm{HU}$, como possíveis artefatos da extração com $\mathrm{NaOH}$, e proposto alternativamente a existência de compostos mais simples estabilizados por interações supramoleculares (Schmidt et al., 2011), e essa polêmica esteja longe de ser resolvida, isso não invalida a relevância do contingente de trabalhos sobre extrações e partição das SHs. Contudo, é necessário obter uma visão mais ampla dos resultados no Brasil sobre a quantificação de $\mathrm{AH}, \mathrm{AF}, \mathrm{HU}$ e seu significado ambiental e 
pedológico. O objetivo deste trabalho foi avaliar a partição quantitativa das frações húmicas em diferentes profundidades, solos, biomas e coberturas vegetais no Brasil, avaliando a adequação de seu uso como indicadores de processos edáficos e efeitos do manejo agrícola.

\section{MATERIAL E MÉTODOS}

\section{Revisão da literatura}

Foi feita uma revisão da literatura sobre solos brasileiros, incluindo teses, dissertações, artigos de periódicos e resumos em anais de congressos científicos, a fim de reunir dados quantitativos do teor de carbono orgânico total do solo (COT) e partição das SHs pelas frações clássicas de solubilidade. Foram compilados os teores de COT, suas porcentagens como frações $\mathrm{AF}$, $\mathrm{AH}$ e HU, bem como a razão $\mathrm{AH} / \mathrm{AF}$. Quando não especificamente determinada, a fração $\mathrm{HU}$ foi calculada por diferença. Embora esse procedimento esteja sujeito a erro de confundimento com frações não humificadas, como a matéria orgânica particulada, tal erro também pode ocorrer onde a humina foi quantificada como o COT do solo residual, após a extração alcalina. Como alguns trabalhos seguiram métodos ligeiramente modificados para pré-tratamento e fracionamento de $\mathrm{SH}$, ou utilizaram diferentes meios de análise de COT, tais informações foram também registradas. Uma vez que as camadas e profundidades analisadas em cada trabalho são variáveis, bem como pela tendência geral de o teor de COT diminuir em profundidade, os dados foram agrupados em intervalos comparáveis de profundidades $(0-5,5-10,0-20,20-50,50-100$ e $>100 \mathrm{~cm})$, mais próximos da camada analisada. Para que não houvesse superposição, um dado referente a uma camada de 0-6 cm, por exemplo, foi alocado no grupo 0-5 cm, mas não simultaneamente nos grupos 5-10 e 0-20 cm. Os dados foram ordenados pelos cinco biomas (Mata Atlântica, Cerrado, Amazônia, Pampa e Caatinga), definidos de acordo com o Instituto Brasileiro de Geografia e Estatística (IBGE). Para as regiões localizadas em zona de transição de biomas, esses foram classificados considerando-se a vegetação nativa descrita no trabalho.

Os dados foram também estratificados pelas sete ordens de solos mais comuns na base de dados (Argissolo, Latossolo, Cambissolo, Planossolo, Neossolo, Gleissolo e Organossolo), conforme o Sistema Brasileiro de Classificação do Solo (Embrapa, 2006). Os principais usos do solo (florestas nativas, pastagem natural, pastagem plantada, eucalipto, culturas perenes e anuais) foram utilizados como variável de ordenação, para determinar eventuais efeitos do manejo do solo na partição de SH. A categoria "florestas nativas" incluiu tanto matas primárias como as secundárias. As fontes utilizadas, os métodos de estudo das SHs, o teor de COT, as ordens de solos, os biomas e os usos do solo podem ser visualizados no quadro 1.

\section{Análises estatísticas}

Para análise dos dados, foi gerada uma matriz de dados (521 x 5), em que as linhas corresponderam aos dados propriamente ditos, ordenados por profundidade, ordem de solo, bioma e uso do solo, e as colunas, às variáveis selecionadas (teor de COT, porcentagens de $\mathrm{AH}, \mathrm{AF}, \mathrm{HU}$ e a razão $\mathrm{AH} / \mathrm{AF}$ ). Quando não expressamente relacionado no trabalho, o teor de $\mathrm{HU}$ foi calculado como a diferença entre COT e AH+AF. Para cada variável, foram calculados a distribuição de frequência e o respectivo teste de normalidade pelo método de Shapiro-Wilk, bem como determinadas as medidas de posição e de dispersão (máximo, mínimo, média, mediana e desvio-padrão). Procedeu-se à análise de correlação de Spearman entre a profundidade média de cada camada e as variáveis anteriormente citadas.

As interações entre as variáveis foram estudadas por uma técnica matemática de análise multivariada e projeção, a análise de componentes principais (ACP), que considera simultaneamente todas as variáveis e permite visão mais ampla do fenômeno do que a abordagem univariada (Moita Neto, 2006). Em termos geométricos, essa técnica realiza uma rotação rígida no sistema de eixos coordenados, fazendo com que os novos eixos resultantes sejam posicionados no sentido de maior variabilidade (Ferreira, 2011). A principal utilidade da ACP é reduzir a dimensionalidade do conjunto de dados, retendo tanta informação quanto possível, num menor número de componentes principais. O primeiro componente principal é a combinação das variáveis que explica a maior proporção da variação total dos dados, o segundo define a segunda maior variação e, assim, sucessivamente até o último componente (Silva \& Sbrissia, 2010).

Para a aplicação da técnica de ACP, foi realizada a padronização das variáveis, que, por serem originalmente expressas em unidades diferentes ou atingirem várias ordens de grandeza, foram escalonadas pela conversão em unidades $\mathrm{Z}$, conforme a equação 1.

$$
Z=(X-X m) / s
$$

em que $\mathrm{Z}$ é o valor padronizado da variável; $\mathrm{X}$, seu valor mensurado; $\mathrm{Xm}$, a média da variável; e s, o respectivo desvio-padrão da amostra. Na matriz de dados, foram realizados testes prévios de KaiserMeyer-Olkin (KMO) e de esfericidade de Bartlett, para avaliar a adequação dos valores de entrada das variáveis para o modelo. A matriz de dados foi considerada adequada para a ACP, de modo que foram realizadas a normalização e ortogonalização dos autovetores extraídos dessa matriz, para garantir solução única e independência mútua às componentes principais. O número total de componentes para o conjunto das variáveis originais foi decidido pela seleção das componentes que sintetizaram variância acumulada em torno de $70 \%$, conforme Ferreira (1996). 
Quadro 1. Bioma, solo, uso do solo e métodos dos trabalhos compilados

\begin{tabular}{|c|c|c|c|c|}
\hline Bioma & Solo & Uso do solo & Fonte & Método COT/Pré-tratamento \\
\hline \multirow[t]{59}{*}{ Mata Atlântica } & Latossolo & $\mathrm{Ca}, \mathrm{Cp}, \mathrm{Pp}, \mathrm{Fl}$ & Almeida (2009) & \\
\hline & Cambissolo & $\mathrm{Cp}, \mathrm{Pp}, \mathrm{Fl}$ & Almeida (2009) & \\
\hline & Neossolo & $\mathrm{Cp}, \mathrm{Pp}, \mathrm{Fl}$ & Almeida (2009) & \\
\hline & Neossolo & $\mathrm{Cp}, \mathrm{Fl}$ & Arend (2010) & $\mathrm{CS}, \mathrm{HCl} / \mathrm{NaOH}$ \\
\hline & Argissolo & Pn & Baldotto et al. (2010) & \\
\hline & Latossolo & Pn & Baldotto et al. (2010) & \\
\hline & Neossolo & $\mathrm{Cp}$ & Baldotto et al. (2010) & \\
\hline & Latossolo & $\mathrm{Fl}, \mathrm{Cp}, \mathrm{Pp}$ & Barreto et al. (2008) & \\
\hline & Organossolo & Pn & Benites et al. (2001) & \\
\hline & Cambissolo & Pn & Benites et al. (2001) & \\
\hline & Neossolo & $\mathrm{Fl}, \mathrm{Pn}$ & Benites et al. (2001) & \\
\hline & Latossolo & $\mathrm{Fl}, \mathrm{Cp}, \mathrm{Pp}$ & Benites et al. (2010) & \\
\hline & Neossolo & $\mathrm{Pn}$ & Benites et al. (2001) & \\
\hline & Cambissolo & $\mathrm{Fl}$ & Benites et al. (2001) & \\
\hline & Latossolo & $\mathrm{Fl}$ & Benites et al. (2001) & \\
\hline & Neossolo & $\mathrm{Fl}$ & Benites et al. (2007) & \\
\hline & Organossolo & $\mathrm{Pp}$ & Campos et al. (2010) & $\mathrm{CS}$ \\
\hline & Organossolo & $\mathrm{Pp}$ & Campos el al. (2009) & $\mathrm{CS}, \mathrm{H}_{3} \mathrm{PO}_{4} / \mathrm{Na}_{4} \mathrm{P}_{2} \mathrm{O}_{2}$ \\
\hline & Argissolo & $\mathrm{Pp}$ & Canellas et al. (2000) & $\mathrm{CUm}, \mathrm{H}_{3} \mathrm{PO}_{4} / \mathrm{Na}_{4} \mathrm{P}_{2} \mathrm{O}_{2}$ \\
\hline & Planossolo & $\mathrm{Pp}$ & Canellas et al. (2000) & $\mathrm{CUm}, \mathrm{H}_{3} \mathrm{PO}_{4} / \mathrm{Na}_{4} \mathrm{P}_{2} \mathrm{O}_{2}$ \\
\hline & Gleissolo & $\mathrm{Pp}$ & Canellas et al. (2000) & CUm, $\mathrm{H}_{3} \mathrm{PO}_{4} / \mathrm{Na}_{4} \mathrm{P}_{2} \mathrm{O}_{2}$ \\
\hline & Cambissolo & $\mathrm{Cp}$ & Canellas et al. (2003) & CUm, $\mathrm{H}_{3} \mathrm{PO}_{4} / \mathrm{Na}_{4} \mathrm{P}_{2} \mathrm{O}_{2}$ \\
\hline & Argissolo & $\mathrm{Ca}, \mathrm{Cp}, \mathrm{Fl}, \mathrm{Pp}$ & Canellas et al. (2004) & $\mathrm{CUm}, \mathrm{H}_{3} \mathrm{PO}_{4} / \mathrm{Na}_{4} \mathrm{P}_{2} \mathrm{O}_{2}$ \\
\hline & Argissolo & $\mathrm{Ca}$ & Canellas \& Façanha (2004) & $\mathrm{CUm}, \mathrm{H}_{3} \mathrm{PO}_{4} / \mathrm{Na}_{4} \mathrm{P}_{2} \mathrm{O}_{2}$ \\
\hline & Argissolo & $\mathrm{Ca}, \mathrm{Cp}, \mathrm{Cp}, \mathrm{Pp}$ & Coelho et al. (2009) & \\
\hline & Organossolo & $\mathrm{Ca}, \mathrm{Pp}, \mathrm{Cp}$ & Conceição et al. (1999) & $\mathrm{CS}, \mathrm{H}_{3} \mathrm{PO}_{4} / \mathrm{Na}_{4} \mathrm{P}_{2} \mathrm{O}_{2}$ \\
\hline & Argissolo & $\mathrm{Pp}$ & Cordeiro (2006) & $\mathrm{CS}$ \\
\hline & Organossolo & $\mathrm{Fl}, \mathrm{Pp}$ & Ebeling et al.(2011) & $\mathrm{CS}$ \\
\hline & Cambissolo & $\mathrm{Cp}, \mathrm{Fl}, \mathrm{Ca}$ & Fontana et al.(2011) & \\
\hline & Organossolo & - & Fontana et al. (2010a) & \\
\hline & Latossolo & $\mathrm{Pp}, \mathrm{Ca}$ & Fontana et al. (2006) & \\
\hline & Latossolo & $\mathrm{Fl}, \mathrm{Ca}, \mathrm{Pp}$ & Fontana et al. (2001) & \\
\hline & Argissolo & $\mathrm{Fl}, \mathrm{Ca}, \mathrm{Pp}$ & Fontana et al. (2001) & \\
\hline & Latossolo & $\mathrm{Fl}, \mathrm{Ca}, \mathrm{Pp}$ & Fontana et al. (2010a) & $\mathrm{CS}$ \\
\hline & Argissolo & $\mathrm{Fl}, \mathrm{Ca}, \mathrm{Pp}$ & Fontana et al. (2010a) & $\mathrm{CS}$ \\
\hline & Planossolo & $\mathrm{Fl}, \mathrm{Cp}$ & Giácomo et al. (2008) & \\
\hline & Latossolo & $\mathrm{Fl}, \mathrm{Ca}$ & Oliveira Jr \& Melo (2000) & \\
\hline & Latossolo & $\mathrm{Fl}, \mathrm{Ca}, \mathrm{Cp}$ & Lima \& Bezerra Neto (2009) & \\
\hline & Cambissolo & $\mathrm{Cp}$ & Loss et al. (2007) & \\
\hline & Gleissolo & $\mathrm{Ca}, \mathrm{Cp}$ & Loss et al. (2007) & \\
\hline & Argissolo & $\mathrm{Cp}, \mathrm{Ca}$ & Loss et al.(2010) & \\
\hline & Argissolo & $\mathrm{Pp}, \mathrm{Ca}, \mathrm{Fl}$ & Loss et al. (2006) & \\
\hline & Argissolo & $\mathrm{Cp}, \mathrm{Ca}$ & Loss et al. (2008) & \\
\hline & Cambissolo & $\mathrm{Fl}$ & Machado et al. (2010) & \\
\hline & Cambissolo & $\mathrm{Fl}$ & Menezes $(2008 b)$ & Cum, $\mathrm{HCl}$ \\
\hline & Neossolo & $\mathrm{Ca}, \mathrm{Fl}$ & Menezes (2008b) & $\mathrm{Cum}, \mathrm{HCl}$ \\
\hline & Cambissolo & $\mathrm{Ca}, \mathrm{Fl}$ & Menezes (2008a) & \\
\hline & Gleissolo & $\mathrm{Ca}$ & Miranda et al. (2007) & \\
\hline & Cambissolo & $\mathrm{Cp}$ & Miranda et al. (2007) & \\
\hline & Argissolo & $\mathrm{Eu}$ & Miranda et al. (2007) & \\
\hline & Planossolo & $\mathrm{Fl}, \mathrm{Pp}$ & Moraes et al. (2008) & \\
\hline & Gleissolo & $\mathrm{Fl}, \mathrm{Pp}$ & Moraes et al. (2008) & \\
\hline & Argissolo & $\mathrm{Fl}, \mathrm{Pp}$ & Moraes et al. (2008) & \\
\hline & Latossolo & $\mathrm{Cp}$ & Partelli et al. (2009) & \\
\hline & Argissolo & $\mathrm{Fl}, \mathrm{Cp}, \mathrm{Pp}$ & Portugal (2008) & \\
\hline & Latossolo & $\mathrm{Fl}, \mathrm{Pn}$ & Santana (2010) & $\mathrm{CS}, \mathrm{HCl}$ \\
\hline & Argissolo & $\mathrm{Ca}, \mathrm{Fl}$ & Schaefer et al. (2002) & \\
\hline & Cambissolo & $\mathrm{Pn}, \mathrm{Cp}$ & Schiavo et al. (2007) & \\
\hline & Cambissolo & $\mathrm{Eu}, \mathrm{Cp}, \mathrm{Pn}$ & Schiavo et al. (2009) & \\
\hline
\end{tabular}


Quadro 1. Cont.

\begin{tabular}{|c|c|c|c|c|}
\hline Bioma & Solo & Uso do solo & Fonte & Método COT/Pré-tratamento \\
\hline \multirow{3}{*}{ Mata Atlântica } & Latossolo & Fl, $\mathrm{Pp}$ & Silva et al. (2010) & \\
\hline & Latossolo & $\mathrm{Fl}, \mathrm{Cp}$ & Silva et al. (2000) & $\mathrm{CS}$ \\
\hline & Organossolo & Pn & Silva et al. (2009) & $\mathrm{CS}$ \\
\hline \multirow[t]{21}{*}{ Amazônia } & Argissolo & Fl, Pn & Araújo et al. (2011) & $\mathrm{CS}$ \\
\hline & Latossolo & $\mathrm{Fl}, \mathrm{Pp}$ & Araújo et al. (2011) & $\mathrm{CS}$ \\
\hline & Argissolo & $\mathrm{Fl}, \mathrm{Pp}$ & Araújo et al. (2004) & \\
\hline & Argissolo & $\mathrm{Fl}$ & Castro (2008) & \\
\hline & Latossolo & $\mathrm{Fl}, \mathrm{Ca}$ & Cunha et al. (2007) & $\mathrm{CS}$ \\
\hline & Latossolo & $\mathrm{Fl}$ & Cunha et al. (2009) & \\
\hline & Organossolo & - & Fontana et al. (2010b) & \\
\hline & Latossolo & $\mathrm{Fl}$ & Longo \& Espíndola (2000) & \\
\hline & Cambissolo & $\mathrm{Fl}, \mathrm{Pp}$ & Loss et al. (2009) & \\
\hline & Cambissolo & $\mathrm{Pn}$ & Melo \& Schaefer (2009) & $\mathrm{CS}$ \\
\hline & Gleissolo & $\mathrm{Pp}$ & Melo (2002) & \\
\hline & Argissolo & $\mathrm{Fp}, \mathrm{Ca}, \mathrm{Pp}$ & Melo (2002) & \\
\hline & Latossolo & $\mathrm{Fl}$ & Melo (2002) & \\
\hline & Argissolo & - & Moreira (2007) & \\
\hline & Latossolo & - & Moreira (2007) & \\
\hline & Neossolo & - & Moreira (2007) & \\
\hline & Cambissolo & - & Moreira (2007) & \\
\hline & Latossolo & - & Moreira (2007) & \\
\hline & Argissolo & $\mathrm{Ca}, \mathrm{Cp}$ & Santos et al. (2009a) & \\
\hline & Argissolo & $\mathrm{Fl}, \mathrm{Cp}$ & Santos et al. (2008) & \\
\hline & Cambissolo & $\mathrm{Fl}, \mathrm{Pp}, \mathrm{Cp}$ & Villani et al. (2010) & Cum, NaI \\
\hline \multirow[t]{10}{*}{ Caatinga } & Neossolo & $\mathrm{Pl}, \mathrm{Pn}$ & Benites et al. (2001) & \\
\hline & Neossolo & $\mathrm{Fl}$ & Benites et al. (2007) & \\
\hline & Argissolo & $\mathrm{Fl}, \mathrm{Cp}, \mathrm{Ca}$ & Cunha et al. ( 2008) & \\
\hline & Organossolo & - & Fontana et al. (2010b) & \\
\hline & Organossolo & $\mathrm{Ca}$ & Campos et al. (2009) & $\mathrm{CS}, \mathrm{H}_{3} \mathrm{PO}_{4}, \mathrm{NA}_{4} \mathrm{P}_{2} \mathrm{O}_{2}$ \\
\hline & Organossolo & $\mathrm{Ca}$ & Campos et al. (2010) & $\mathrm{CS}$ \\
\hline & Latossolo & $\mathrm{Fl}, \mathrm{Ca}$ & Cunha et al. (2001) & \\
\hline & Neossolo & $\mathrm{Fl}$ & Benites et al. (2007) & \\
\hline & Organossolo & - & Fontana et al. (2010b) & \\
\hline & Latossolo & - & Freitas et al. ( 2009) & \\
\hline \multirow[t]{11}{*}{ Cerrado } & Latossolo & $\mathrm{Ca} \mathrm{Cp}, \mathrm{Fl}$ & Oliveira Jr \& Melo (2000) & \\
\hline & Latossolo & $\mathrm{Cp}$ & Marchiori Jr et al. (2008) & \\
\hline & Latossolo & $\mathrm{Fl}$ & Longo \& Espíndola (2000) & \\
\hline & Latossolo & $\mathrm{Fl}$ & Machado et al. (2009) & \\
\hline & Latossolo & $\mathrm{Pp}, \mathrm{Cp}, \mathrm{Ca}$ & Santos et al. (2010) & \\
\hline & Cambissolo & $\mathrm{Pn}$ & Santos et al. (2009b) & \\
\hline & Organossolo & $\mathrm{Pn}$ & Silva et al. (2009) & $\mathrm{CS}$ \\
\hline & Planossolo & $\mathrm{Pn}, \mathrm{Ca}$ & Farias et al. (2010) & $\mathrm{CS}, \mathrm{HCl}$ \\
\hline & Organossolo & - & Fontana et al. (2010b) & \\
\hline & Neossolo & $\mathrm{Fl}, \mathrm{Ca}$ & Menezes (2008a) & $\mathrm{Cum}, \mathrm{HCl}$ \\
\hline & Neossolo & $\mathrm{Fl}, \mathrm{Ca}$ & Menezes (2008a) & Cum, $\mathrm{HCl}$ \\
\hline \multirow[t]{6}{*}{ Pampa } & Cambissolo & $\mathrm{Fl}, \mathrm{Ca}$ & Menezes (2008b) & Cum, $\mathrm{HCl}$ \\
\hline & Planossolo & $\mathrm{Ca}, \mathrm{Pn}$ & Rosa et al. (2008) & \\
\hline & Argissolo & $\mathrm{Eu}, \mathrm{Pn}$ & Soares (2009) & \\
\hline & Neossolo & $\mathrm{Eu}, \mathrm{Pn}$ & Soares (2009) & \\
\hline & Cambissolo & $\mathrm{Eu}, \mathrm{Pn}$ & Soares (2009) & \\
\hline & Argissolo & $\mathrm{Eu}, \mathrm{Pn}$ & Soares (2009) & \\
\hline
\end{tabular}

Pp: pastagem plantada; Pn: pastagem natural; Ca: cultura anual; Cp: cultura perene; Fl: Floresta; Eu: Eucalipto; CS: combustão seca; Cum: combustão úmida. Obs: Todos os autores não fizeram pré-tratamento e usaram o método de combustão úmida para determinar o COT e $\mathrm{NaOH}$ para extração das $\mathrm{SH}$, exceto os citados no quadro. 
Para obter melhor visualização das variáveis, que representam cada fator, foi realizada uma rotação ortogonal nos eixos fatoriais, que coloca os fatores em posições associáveis somente às variáveis relacionadas ao fator. Nessa solução analítica, as cargas fatoriais são alteradas, enquanto as comunalidades (soma de quadrados das linhas da matriz de cargas) e as proporções das explicações (soma de quadrados de cada coluna tomada em relação à variação total) ficam inalteradas (Ferreira, 2011). Selecionaram-se dois componentes principais derivados por rotação varimax, que é uma transformação ortogonal aplicada à matriz de cargas fatoriais (correlação entre os fatores e variáveis originais). Para a matriz de dados deste estudo, notou-se que o primeiro componente concentrou $37,2 \%$ da variância total e o segundo, $30,8 \%$, acumulando $68 \%$. Os fatores obtidos na ACP foram associados às amostras originais, estratificados e identificados pelas diferentes profundidades, pela unidade taxonômica (ordem) de solos, pelos biomas e pelos usos do solo. Todas as operações matemáticas e estatísticas foram realizadas com auxílio do programa SPSS 15.0 (Statistical Package for Social Sciences) e das planilhas eletrônicas. A base de dados utilizada está disponível a eventuais interessados.

\section{RESULTADOS E DISCUSSÃO}

\section{Distribuição de frequência e estatística descritiva}

$\mathrm{Na}$ figura 1, são apresentadas as distribuições de frequência dos valores de $\mathrm{COT}, \mathrm{HU}, \mathrm{AH}, \mathrm{AF}$ e AH/AF compilados da literatura, incluindo todos os dados em suas respectivas profundidades originais. A variável HU foi a única que apresentou distribuição normal $(p=0,157)$ (Figura $1 b)$, pois o teste de Shapiro-Wilk evidenciou $\mathrm{p}<0,05$ para COT, $\mathrm{AH}, \mathrm{AF}$ e AH/AF. A distribuição assimétrica à direita dos valores de COT (Figura 1a) indica que a maioria dos solos e das camadas representados apresenta teores entre $0 \mathrm{e}$ $20 \mathrm{~g} \mathrm{~kg}^{-1}$, refletindo os teores típicos das ordens Latossolo e Argissolo, que representam cerca de $60 \%$ dos dados compilados e o número considerável de camadas subsuperficiais. A distribuição assimétrica de COT reflete ainda a presença de solos com elevados teores de COT (Organossolos), visível como a longa cauda da figura 1a que expõe pequeno número de camadas com teor $>500 \mathrm{~g} \mathrm{~kg}^{-1}$.

Esperou-se que a partição de SH apresentasse distribuição mais próxima da normalidade do que a do teor de COT, por teoricamente sofrer menor efeito da profundidade e evidenciar menor amplitude de variação. De fato, a distribuição das frações $\mathrm{AH}$ e $\mathrm{AF}$, embora igualmente não-normais, apresentou menor assimetria à direita do que o COT, com a maior parte dos dados com valores menores do que $25 \%$ (Figura 1c,d). Isso sugere que o teor combinado das frações $\mathrm{AH}$ e $\mathrm{AF}$ é, na maioria dos solos brasileiros, menor do que o teor de HU, de acordo com Fontana et al. (2008). Segundo Stevenson (1994), isso é atribuível à maior estabilidade da $\mathrm{HU}$, dentre todas as formas do COT.

Os teores de COT variaram largamente entre 1,14 e $477,0 \mathrm{~g} \mathrm{~kg}^{-1}$ (Quadro 2), confirmando a ampla representatividade da base de dados, que inclui desde Neossolos Quartzarênicos, com baixíssimos teores de COT em profundidade, até os Organossolos. Tal amplitude ocorre também para a partição das SHs: os percentuais médios da fração $\mathrm{AF}$ variaram entre 1,0 e $74,7 \%$; os da fração AH, entre 0,2 e $61,5 \%$; e os da fração HU, entre 4,3 e $97,2 \%$ do COT. Para a relação $\mathrm{AH} / \mathrm{AF}$, os valores variaram entre 0,02 e 6,55, sendo em geral $<1,8$. Dessa forma, pode-se considerar que a base de dados é abrangente e variável o suficiente para as análises propostas.
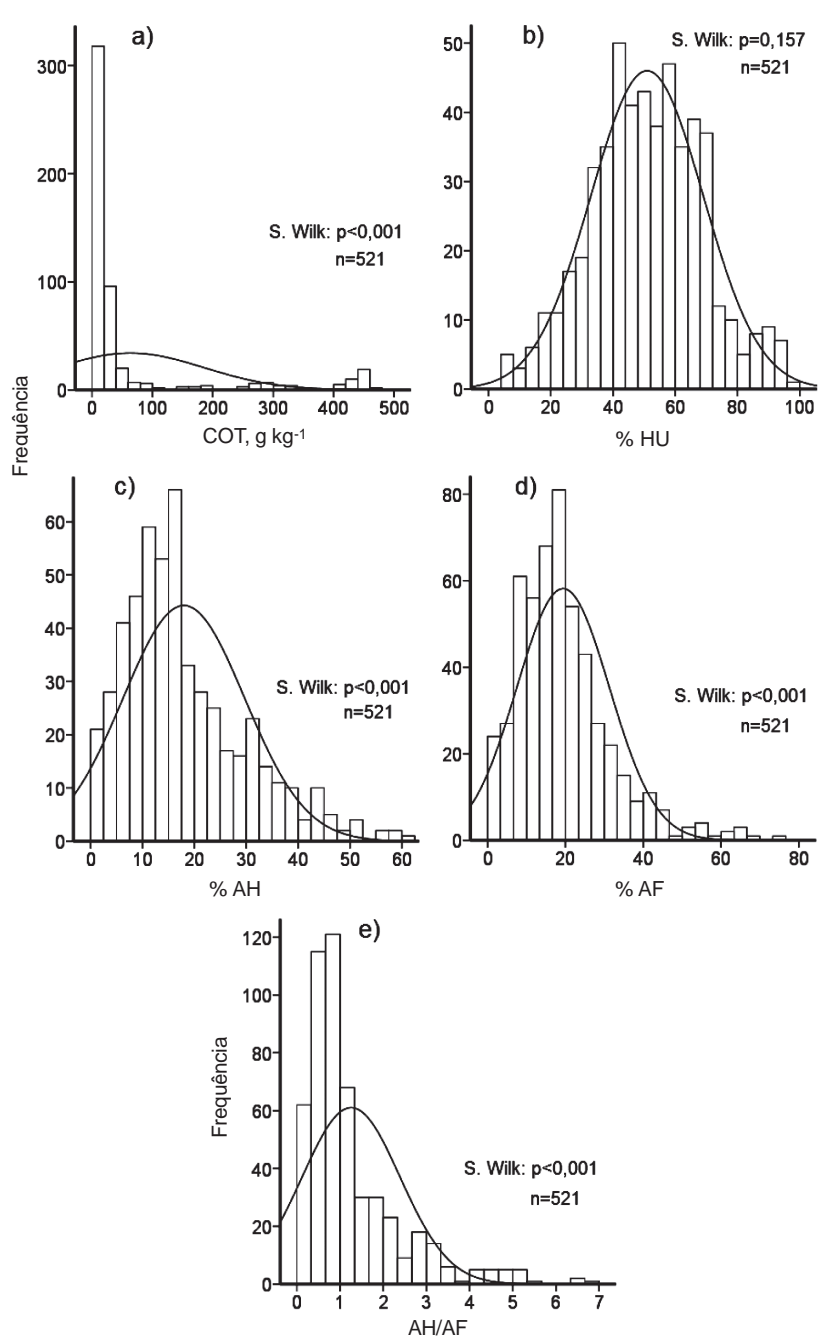

Figura 1. Distribuição geral de frequência de teores de carbono orgânico total (COT) e sua porcentagem na forma de ácidos húmicos (AH), ácidos fúlvicos (AF), humina (HU) e razão $\mathrm{AH}$ / AF, em todas as profundidades. 
Quadro 2. Estatística descritiva das variáveis analisadas: carbono orgânico total (COT), ácidos húmicos (AH), ácidos fúlvicos (AF), humina (HU) e relação $\mathrm{AH} / \mathrm{AF}$. N: número de observações

\begin{tabular}{|c|c|c|c|c|c|c|c|c|}
\hline Variável & Prof. & $\mathbf{N}$ & Máximo & Mínimo & Média & Mediana & Desvio-padrão & S. Wilk Prob. \\
\hline & $\mathrm{cm}$ & & & & & & & \\
\hline \multirow[t]{6}{*}{$\operatorname{COT}\left(\mathrm{g} \mathrm{kg}^{-1}\right)$} & $0-5$ & 114 & 86,90 & 5,90 & 20,11 & 14,81 & 13,50 & 0,001 \\
\hline & $5-10$ & 66 & 98,90 & 5,30 & 17,57 & 11,93 & 16,90 & $<0,001$ \\
\hline & $0-20$ & 109 & 98,00 & 5,40 & 24,49 & 20,30 & 17,57 & $<0,001$ \\
\hline & $20-50$ & 128 & 448,00 & 1,14 & 42,04 & 7,55 & 106,62 & $<0,001$ \\
\hline & $50-100$ & 55 & 452,00 & 1,50 & 132,05 & 4,76 & 184,24 & $<0,001$ \\
\hline & $>100$ & 35 & 477,00 & 1,66 & 296,09 & 292,70 & 152,70 & 0,002 \\
\hline \multirow[t]{6}{*}{$\mathrm{AH}(\%)$} & $0-5$ & 114 & 48,11 & 2,64 & 17,75 & 15,47 & 8,67 & 0,001 \\
\hline & $5-10$ & 66 & 27,41 & 1,85 & 13,22 & 14,30 & 5,97 & 0,192 \\
\hline & $0-20$ & 109 & 59,18 & 1,74 & 20,76 & 18,54 & 13,01 & 0,001 \\
\hline & $20-50$ & 128 & 61,54 & 1,92 & 17,11 & 15,51 & 12,00 & $<0,001$ \\
\hline & $50-100$ & 55 & 44,37 & 0,23 & 14,39 & 10,40 & 13,11 & $<0,001$ \\
\hline & $>100$ & 35 & 50,86 & 4,32 & 22,80 & 27,92 & 13,10 & 0,003 \\
\hline \multirow[t]{6}{*}{$\mathrm{AF}(\%)$} & $0-5$ & 114 & 52,14 & 2,40 & 17,08 & 15,98 & 7,78 & 0,001 \\
\hline & $5-10$ & 66 & 42,50 & 4,78 & 16,71 & 16,67 & 6,82 & 0,021 \\
\hline & $0-20$ & 109 & 47,50 & 3,00 & 17,69 & 17,14 & 9,46 & 0,009 \\
\hline & $20-50$ & 128 & 62,93 & 1,40 & 23,14 & 22,23 & 12,16 & 0,001 \\
\hline & $50-100$ & 55 & 64,44 & 1,00 & 17,49 & 9,47 & 16,51 & $<0,001$ \\
\hline & $>100$ & 35 & 74,66 & 6,03 & 27,18 & 20,14 & 20,48 & $<0,001$ \\
\hline \multirow[t]{6}{*}{$\mathrm{AH} / \mathrm{AF}$} & $0-5$ & 114 & 3,25 & 0,24 & 1,16 & 0,91 & 0,65 & 0,001 \\
\hline & $5-10$ & 66 & 2,06 & 0,15 & 0,85 & 0,85 & 0,39 & 0,006 \\
\hline & $0-20$ & 109 & 6,44 & 0,25 & 1,36 & 1,06 & 1,00 & $<0,001$ \\
\hline & $20-50$ & 128 & 4,80 & 0,04 & 1,02 & 0,73 & 0,99 & $<0,001$ \\
\hline & $50-100$ & 55 & 6,55 & 0,02 & 1,66 & 0,81 & 1,80 & $<0,001$ \\
\hline & $>100$ & 35 & 5,61 & 0,15 & 1,78 & 0,49 & 1,76 & $<0,001$ \\
\hline \multirow[t]{6}{*}{ HU (\%) } & $0-5$ & 114 & 90,98 & 18,10 & 54,86 & 56,32 & 16,62 & 0,059 \\
\hline & $5-10$ & 66 & 92,45 & 12,89 & 57,96 & 58,43 & 18,99 & 0,244 \\
\hline & $0-20$ & 109 & 97,25 & 21,57 & 51,63 & 48,78 & 15,62 & 0,031 \\
\hline & $20-50$ & 128 & 93,75 & 10,71 & 45,80 & 44,23 & 19,37 & 0,032 \\
\hline & $50-100$ & 55 & 94,75 & 6,91 & 48,60 & 46,84 & 17,61 & 0,005 \\
\hline & $>100$ & 35 & 60,04 & 4,26 & 46,05 & 54,09 & 17,69 & $<0,001$ \\
\hline
\end{tabular}

O efeito da profundidade: correlações de Spearman ( $\rho)$ e Análise de Componentes Principais

No quadro 2, observa-se aparente aumento dos teores médios e medianos de COT em maiores profundidades, o que não é usual. Uma vez que testes de médias por profundidades não podem ser aplicados à variável COT em razão da não-normalidade dos dados, mesmo ao considerar cada classe de profundidade em separado (Quadro 2), foram realizadas correlações de Sperman entre a profundidade média das camadas e o teor de COT, no todo e separadamente por ordem de solo (Quadro 3). Nota-se que a correlação COT x profundidade em geral não é significativa, porque o teor de COT decrescente em profundidade na maioria dos solos é contrabalançado pela inexistente correlação para os Organossolos, Neossolos e Gleissolos. Assim, embora os Organossolos compreendam minoria dos solos brasileiros, esses formam $14 \%$ da base de dados por despertarem interesse dos pesquisadores em $\mathrm{SH}$; seus altos teores de COT em profundidade impõem a tendência de aumento do teor de COT (e os desviospadrão) ao longo do perfil. A super-representação dos Organossolos deve ser considerada na interpretação dos dados sobre COT, mas não necessariamente sobre a partição das SHs. No quadro 2, também estão apresentados os percentuais médios e medianos da fração $\mathrm{AF}$, aparentemente maiores na camada abaixo de $100 \mathrm{~cm}$, o que é confirmado pela correlação de Sperman para as ordens dos Latossolos e Organossolos ( $\rho=0,251$ e $\rho=0,364$, respectivamente, $p<0,001)$ (Quadro 2). A fração HU ( $\rho=-0,192, p<0,001)$ e a razão AH/AF $(\rho=-0,097, p<0,001)$ também diminuem em profundidade, enquanto a fração $\mathrm{AH}$ se mantém constante $(\rho=0,003, p<0,94)$. 
O efeito da profundidade pode também ser verificado na ACP. Na figura 2, está apresentada a alocação das variáveis $\mathrm{COT}, \mathrm{AH}, \mathrm{AF}$ e $\mathrm{HU}$ ao longo dos dois eixos, que é utilizada como referência à interpretação dos dados estratificados na figura 3. A variável $\mathrm{AH} / \mathrm{AF}$ foi retirada para aumentar a adequação dos dados à análise de componentes principais pelo teste KMO. Além disso, as cargas (loadings) da ACP com a variável $\mathrm{AH} / \mathrm{AF}$ não aumentam a explicação das tendências dos escores, uma vez que essa razão influenciou a dispersão no mesmo sentido que $\mathrm{AH}$ e no sentido contrário à variável AF. Assim, de acordo com a figura 2 , o fator 1 (eixo horizontal) é mais fortemente controlado pelas frações AF e HU, pois distâncias maiores da origem do eixo indicam maiores valores dessas variáveis, enquanto o fator 2 (eixo vertical) depende mais estreitamente do teor de COT e AH.

A grande dispersão dos dados ordenados por profundidade ao longo dos eixos é apresentada na figura 3. Vários pontos referentes às profundidades abaixo de $20 \mathrm{~cm}$ aparecem no topo dos quadrantes superiores; uma vez que essa é a locação da variável COT na figura 2, isso reflete o efeito dos altos teores de COT em camadas profundas dos Organossolos presentes nessa base de dados. Porém, de modo geral, observase que a dispersão de pontos de todas as profundidades na direção das demais variáveis $\mathrm{AH}, \mathrm{AF}$ e HU sugere não existir outra tendência clara de aumento de teores de $\mathrm{AF}$ ou $\mathrm{AH}$ ao longo dos perfis da maioria dos solos, o que também é verificado no quadro 3.

\section{O efeito do tipo de solo, bioma e uso do solo:} Análise de Componentes Principais

Com relação à ordem taxonômica dos solos, observase que os pontos representativos dos Organossolos estão situados principalmente nos quadrantes superiores do fator 1 (Figura 3), de acordo com os

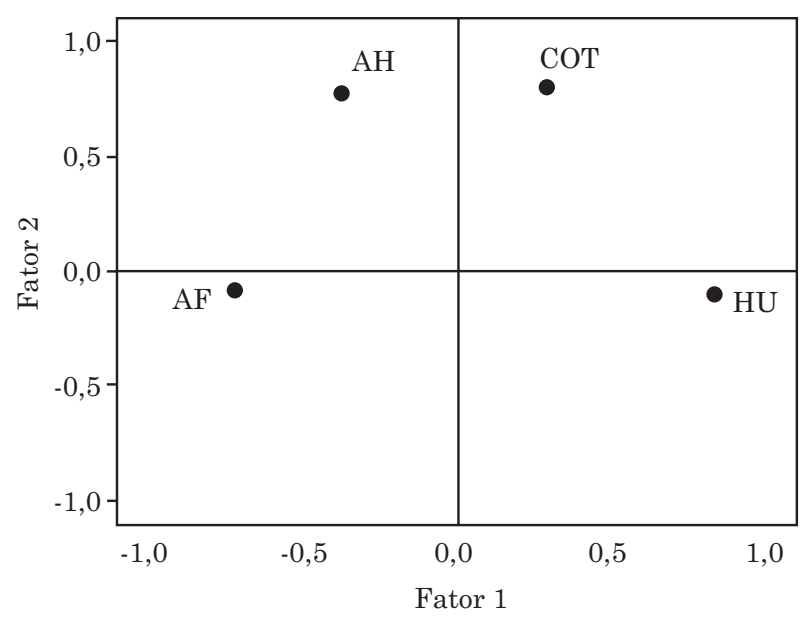

Figura 2. Comportamento das variáveis na análise de componentes principais: carbono orgânico total (COT), ácidos húmicos (AH), ácidos fúlvicos (AF) e humina (HU). maiores teores de COT observados para essa ordem e evidenciados claramente no quadro 3. Os Planossolos, com menores teores médios de COT (Quadro 4), aparecem dispersos no extremo oposto aos Organossolos na figura 3. Os altos teores médios de AH nos Neossolos (Quadro 4) são evidenciados pelo agrupamento desses pontos rumo à posição $\mathrm{AH}$ no quadrante superior esquerdo. No entanto, para as demais ordens, parece não haver nítida discriminação caracterizada apenas pelos teores de COT e partição das $\mathrm{SH}$. O agrupamento das ordens Latossolos e Argissolos, com tendência a apresentarem teores baixos de AH (Figuras 2 e 3), reforça a noção de pouca diferença na partição das SHs nos solos predominantes no Brasil.

Os teores de HU foram em média superiores à combinação $\mathrm{AH}+\mathrm{AF}$ na maioria das ordens de solos estudados, com exceção para o Cambissolo, Gleissolo, Planossolo e Neossolos (Quadro 4), o que também pode ser visualizado na ACP pelo afastamento dos pontos desses solos da locação HU (Figuras 2 e 3). Segundo Canellas \& Santos (2005), tais solos se encontrariam em estádio inicial de humificação, com teores de HU inferiores a $45 \%$. Os baixos valores de HU nos Neossolos, predominantemente Quartzarênicos, podem ser em razão da maior importância do COT particulado (associado à fração areia) e menor sorção das SHs pelo baixo teor de argila, favorecendo o processo de decomposição e lixiviação, diferente do que ocorre em solos argilosos, onde as SHs são estabilizadas (Zinn et al., 2007). Nota-se que a relação AH/AF apresentou os maiores valores nos Organossolos $(2,30)$ e Neossolos $(1,71)$ (Quadro 4). Canellas \& Santos (2005) afirmam que em geral os solos mais arenosos apresentam maiores relações $\mathrm{AH} / \mathrm{AF}$ por causa da perda seletiva da fração $\mathrm{AF}$, mais solúvel.

Os valores médios (incluindo todas as profundidades) de COT, AH, AF, $\mathrm{HU}$ e AH/AF estratificados pelos biomas são apresentados no quadro 3, enquanto a alocação dos pontos pela ACP pode ser observada na figura 3. O bioma Mata Atlântica apresentou aparentemente os maiores teores médios de COT na base de dados. Embora os pontos referentes a este bioma sejam os mais espalhados ao longo dos eixos, pode ser evidenciado na figura $3 \mathrm{um}$ agrupamento de pontos próximo à locação da variável COT nos quadrantes superiores, referentes aos Organossolos lá existentes. Os teores médios de COT em solos da Caatinga e Amazônia foram os menores (Quadro 3), o que também pode ser visto na ACP pelos pontos nitidamente afastados da posição COT. Muitos pontos referentes ao bioma Pampa estão alinhados entre o centro e a posição AH da figura 2, de acordo com os aparentemente maiores teores médios dessa fração (Quadro 4).

Quando os dados foram ordenados por uso do solo (Figura 3), observou-se que os pontos referentes a pastagens naturais concentraram-se no alto do quadrante superior direito, isto é, em direção que demonstra altos teores de COT nos Organossolos. 

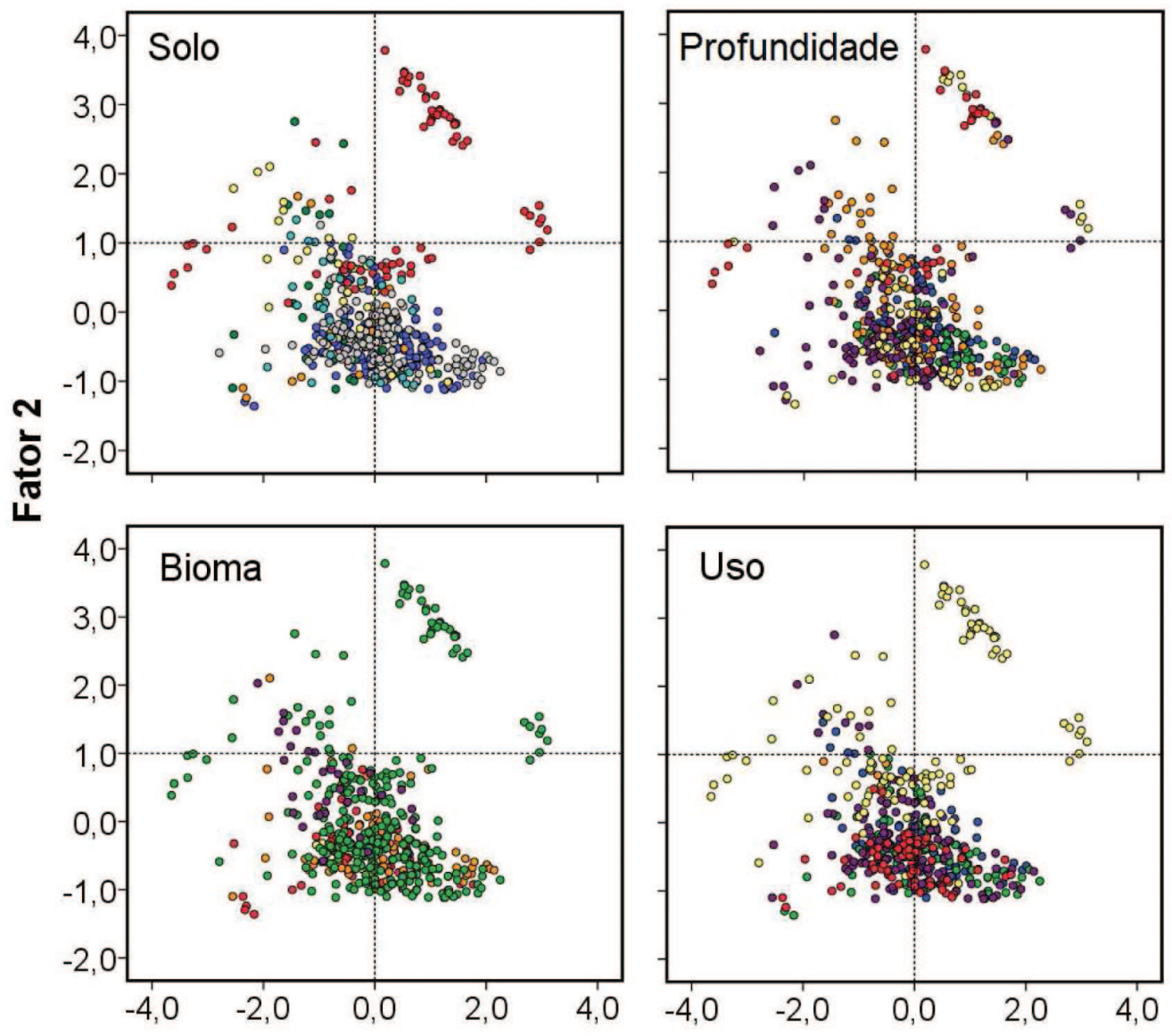

Fator 1
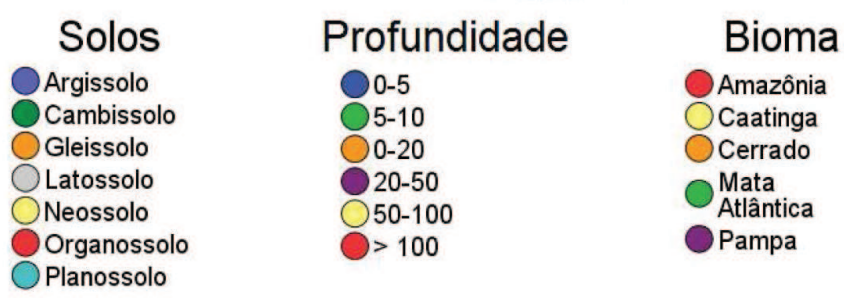

Uso

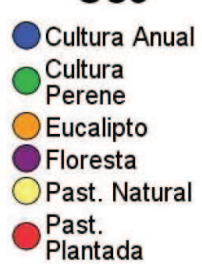

Figura 3. Escores das frações percentuais das SHs e dos teores de COT pela análise de componentes principais, estratificados por profundidade, bioma, ordem de solo e uso do solo.

Quadro 3. Coeficientes de correlação de Spearman ( $\rho)$ entre a profundidade dos solos e os teores de carbono orgânico total (COT), ácido húmico (AH), ácido fúlvico (AF), humina (HU) e relação ácido húmico/ácido fúlvico (AH/AF)

\begin{tabular}{lrlllll}
\hline Solo/Profundidade & $\mathbf{n}$ & COT & AH & AF & AH/AF & HU \\
\hline Argissolo & 163 & $-0,534^{* *}$ & $-0,102$ & 0,115 & $-0,171^{*}$ & $-0,327^{* *}$ \\
Cambissolo & 40 & $-0,381^{*}$ & $-0,181$ & 0,114 & $-0,166$ & $-0,022$ \\
Gleissolo & 16 & $-0,393$ & $-0,558^{*}$ & 0,472 & $-0,467$ & $-0,769^{* *}$ \\
Latossolo & 170 & $-0,702^{* *}$ & 0,072 & $0,251^{* *}$ & $-0,164^{*}$ & $-0,238^{* *}$ \\
Neossolo & 28 & $-0,275$ & $0,461^{*}$ & 0,153 & $0,405^{*}$ & $-0,693^{* *}$ \\
Organossolo & 73 & 0,023 & 0,142 & $0,364^{* *}$ & $-0,124$ & $-0,367^{* *}$ \\
Planossolo & 31 & $-0,831^{* *}$ & $-0,645^{* *}$ & $-0,172$ & $-0,496^{* *}$ & 0,067 \\
Total & 521 & $-0,053$ & $-0,038$ & $0,109^{*}$ & $-0,097^{*}$ & $-0,192^{* *}$ \\
\hline
\end{tabular}

* e ** significativo a 0,05 e 0,01 , respectivamente. 
Quadro 4. Valores médios de carbono orgânico total (COT), ácidos húmicos (AH), ácidos fúlvicos (AF), humina (HU) e razão AH/AF, ordenados por bioma, ordem de solos e uso da terra, incluindo todas as profundidades (desvio-padrão entre parênteses). n: número de observações

\begin{tabular}{|c|c|c|c|c|c|c|}
\hline Classificação & $\mathbf{n}$ & COT & $\mathbf{A H}$ & $\mathbf{A F}$ & $\mathbf{A H} / \mathbf{A F}$ & HU \\
\hline \multicolumn{7}{|l|}{ Solo } \\
\hline Argissolo & 163 & $11,2(7,3)$ & $15,4(8,8)$ & $18,3(9,8)$ & $0,98(0,64)$ & $55,0(16,1)$ \\
\hline Cambissolo & 40 & $41,1(50,3)$ & $19,2(14,3)$ & $21,9(13,2)$ & $1,11(1,14)$ & $40,22(13,0)$ \\
\hline Gleissolo & 16 & $15,9(15,8)$ & $19,0(14,3)$ & $23,2(14,8)$ & $1,19(0,92)$ & $39,6(18,9)$ \\
\hline Latossolo & 170 & $18,2(15,2)$ & $15,0(7,3)$ & $18,7(9,4)$ & $0,99(0,72)$ & $54,0(16,9)$ \\
\hline Neossolo & 28 & $34,7(21,6)$ & $31,0(16,4)$ & $19,0(9,5)$ & $1,71(1,00)$ & $36,6(16,9)$ \\
\hline Organossolo & 73 & $340,9(116,5)$ & $23,2(14,7)$ & $22,5(19,0)$ & $2,30(1,98)$ & $53,8(20,9)$ \\
\hline Planossolo & 31 & $11,0(9,7)$ & $21,9(14,4)$ & $16,9(9,8)$ & $1,46(0,97)$ & $37,8(12,6)$ \\
\hline \multicolumn{7}{|l|}{ Profundidade $(\mathrm{cm})$} \\
\hline $0-5$ & 114 & $20,1(13,5)$ & $17,7(8,7)$ & $17,1(7,8)$ & $1,16(0,65)$ & $54,9(16,6)$ \\
\hline $5-10$ & 66 & $17,6(16,9)$ & $13,2(6,0)$ & $16,7(6,8)$ & $0,84(0,39)$ & $58,0(19,0)$ \\
\hline $0-20$ & 123 & $53,3(92,1)$ & $21,9(13,5)$ & $17,7(9,3)$ & $1,46(1,16)$ & $51,2(15,8)$ \\
\hline $20-50$ & 128 & $42,0(106,6)$ & $17,1(12,0)$ & $23,1(12,2)$ & $1,02(0,98)$ & $45,8(19,4)$ \\
\hline $50-100$ & 55 & $132,0(184,2)$ & $14,4(13,1)$ & $17,5(16,5)$ & $1,66(1,80)$ & $48,6(17,6)$ \\
\hline$>100$ & 35 & $296,0(152,7)$ & $22,8(13,0)$ & $27,18(20,4)$ & $1,78(1,75)$ & $46,0(17,7)$ \\
\hline \multicolumn{7}{|l|}{ Biomas } \\
\hline Amazônia & 79 & $13,0(7,9)$ & $14,3(7,5)$ & $22,7(11,9)$ & $0,76(0,48)$ & $48,6(18,9)$ \\
\hline Caatinga & 6 & $8,0(1,4)$ & $13,7(4,6)$ & $20,8(7,3)$ & $0,66(0,27)$ & $41,3(11,8)$ \\
\hline Cerrado & 81 & $29,0(67,7)$ & $15,6(9,1)$ & $17,9(11,7)$ & $1,28(1,07)$ & $54,6(18,1)$ \\
\hline Mata Atlântica & 325 & $89,3(144,4)$ & $18,1(12,1)$ & $18,7(12,1)$ & $1,33(1,25)$ & $51,6(17,8)$ \\
\hline Pampa & 30 & $19,1(11,4)$ & $33,8(10,8)$ & $22,4(9,6)$ & $1,80(0,87)$ & $41,3(16,2)$ \\
\hline \multicolumn{7}{|l|}{ Uso do solo } \\
\hline Cultura anual & 93 & $12,4(9,7)$ & $17,9(9,7)$ & $15,3(6,3)$ & $1,41(0,97)$ & $54,8(16,3)$ \\
\hline Cultura perene & 99 & $14,5(8,2)$ & $14,7(9,8)$ & $16,5(9,4)$ & $0,96(0,54)$ & $53,4(18,0)$ \\
\hline Eucalipto & 6 & $17,6(5,6)$ & $31,8(12,0)$ & $31,4(11,5)$ & $1,21(0,75)$ & $53,5(8,7)$ \\
\hline Floresta & 144 & $21,6(29,3)$ & $16,6(10,3)$ & $21,2(10,3)$ & $0,89(0,59)$ & $49,3(17,5)$ \\
\hline Pastagem natural & 110 & $238,1(174,0)$ & $25,9(14,6)$ & $21,6(16,6)$ & $2,17(1,77)$ & $49,0(20,4)$ \\
\hline Past. plantada & 69 & $14,9(16,7)$ & $11,8(6,0)$ & $20,8(12,9)$ & $0,76(0,52)$ & $48,4(17,5)$ \\
\hline Total & 521 & $63,4(121,8)$ & $18,0(11,7)$ & $19,4(11,9)$ & $1,25(1,13)$ & $50,9(18,1)$ \\
\hline
\end{tabular}

Simultaneamente, as pastagens naturais ocuparam pontos no quadrante superior esquerdo, na direção centro-AH, evidenciando os altos valores médios de AH também apresentados no quadro 3. Freitas et al. (2009) propõem que os altos teores de COT frequentemente encontrados em pastagens naturais se devem à incorporação da abundante biomassa radicular no solo na fração HU. No entanto, não somente é possível que parte da matéria orgânica particulada não-humificada seja computada como humina em muitos estudos, como também os pontos referentes a pastagens naturais também se espalham por outras áreas do gráfico, o que dificulta a identificação de eventual partição preferencial de SH nesse uso do solo.

Da mesma forma, o agrupamento central dos demais usos do solo não permite distinguir, na figura 3, tendências específicas em teores de COT e partição das SHs. Cerri \& Volkoff (1988), ao estudar os solos de todo Brasil, observaram que apenas o húmus do horizonte A está em equilíbrio com a atual vegetação do solo, enquanto o que está em maior profundidade não é influenciado pelo uso do solo, parecendo ter reflexo nessa base de dados que utiliza muitas camadas subsuperficiais. Igualmente, Nascimento et al. (1993), comparando Cerrado nativo e áreas cultivadas (12-20 anos), e Antunes et al. (2009), em solo cultivado por até 14 anos no norte de Minas Gerais, não encontraram diferenças na partição das SHs, concluindo que o processo de humificação independe do uso do solo. Canellas \& Santos (2005) ressaltam ainda a limitação do uso de SH como indicadores da qualidade do solo, já que os processos envolvidos são lentos, nem todos os resíduos dos processos de decomposição são convertidos em SH e nem todas as SHs recentes são retidas no solo. Embora alguns autores como Teixeira et al. (2010) proponham o uso de teores de AF, AH e 
HU como indicadores edáficos de mudanças no uso do solo, tal proposição não encontrou apoio neste trabalho e nas referências supracitadas. Tal aparente insensibilidade das SHs talvez se deva ao fato de o cultivo interferir principalmente na matéria orgânica particulada ou leve, ainda pouco alterada, ou porque as SHs sejam efetivamente estáveis ao cultivo ou influenciadas similarmente por práticas agrícolas.

\section{CONCLUSÕES}

1. A fração humina, nos Argissolos, Latossolos e Organossolos, contribuiu com pelo menos metade do COT e tendeu a diminuir em profundidade. Para os Latossolos e Organossolos, a fração AF apresentou tendência de aumento em profundidade. Em Neossolos, a fração AH aumentou em profundidade, mas diminuiu nos Gleissolos e Planossolos. De maneira geral, a razãoAH/AF diminui com a profundidade.

2. Os resultados da ACP sugeriram que os diferentes biomas e usos do solo, embora apresentem algumas diferenças importantes nos teores de COT, não interferiram consistentemente na partição quantitativa das $\mathrm{SH}$ s nas frações $\mathrm{AH}, \mathrm{AF}$ e $\mathrm{HU}$.

3. A ACP auxiliou na identificação das diferenças mais evidentes entre teores de COT entre ordens de solo, onde são perceptíveis os baixos teores de COT, em Latossolos e Argissolos, e altos teores, em Organossolos. Foi possível identificar os baixos teores de HU em Neossolos e Gleissolos.

4. Parece haver baixo potencial do uso da mera partição quantitativa das SHs como indicador sintético e consistente de efeitos do manejo agrícola ou de ambientes. No entanto, a partição das SHs retém potencial para discriminar processos pedogenéticos em algumas ordens taxonômicas de solos.

\section{AGRADECIMENTOS}

Ao CNPq e à FAPEMIG, pelas bolsas de mestrado e doutorado concedidas. Ao CNPq, pelos recursos utilizados (projeto CNPq 474045/2010-2). A um revisor anônimo e ao editor associado, pelo trabalho minucioso que resultou em melhoria expressiva deste manuscrito.

\section{LITERATURA CITADA}

ALMEIDA, L.G.F. Caracterização do solo com diferentes usos e composição florística no Vale do Mucuri-MG. Diamantina, Universidade Federal dos Vales do Jequitinhonha e Mucuri. 2009. 75p. (Dissertação de Mestrado)
ANTUNES, R.C.C.; PEGORARO, R.F.; GONÇALVES, C.; DIAS, D.G.; FIGUEIREDO, L.H.A.F. \& FALCÃO, G. Estoque de carbono e nitrogênio nas substâncias húmicas de solos submetidos a diferentes cultivos no Norte de Minas Gerais. In: CONGRESSO BRASILEIRO DE CIÊNCIA DO SOLO, 32., Fortaleza, 2009. Anais... Fortaleza, Sociedade Brasileira de Ciência do Solo, 2009. CD-ROM

ARAÚJO, E.A.; LANI, J.L.; AMARAL, E.F. \& GUERRA, A. Uso da terra e propriedades físicas e químicas de um Argissolo Amarelo distrófico na Amazônia Ocidental. R. Bras. Ci. Solo, 28:307-315, 2004.

ARAÚJO, E.A.; KER, J.C.; MENDONÇA, E.S.; SILVA, I.R. \& OLIVEIRA, E.K. Impacto da conversão florestapastagem nos estoques e na dinâmica do carbono e substâncias húmicas do solo no bioma Amazônico. Acta Amaz., 41:103-114, 2011.

AREND, K. Substâncias húmicas e formas de cobre em solos de áreas de videira. Santa Maria, Universidade Federal de Santa Maria, 2010. 116p. (Tese de Doutorado)

BALDOTTO, M.A.; CANELA, M.C.; CANELLAS, L.P.; DOBBS, L.B. \& VELLOSSO, A.C.X. Redox index of soil carbon stability. R. Bras. Ci. Solo, 34:1543-1551, 2010.

BARRETO, A.C.; FREIRE, M.B.G.S.; NACIF, P.G.S.; ARAÚJO, Q.R.; FREIRE, F.J. \& INÁCIO, E.S.B. Fracionamento químico e físico do carbono orgânico total em um solo de mata submetido a diferentes usos. R. Bras. Ci. Solo, $32: 1471-1478,2008$.

BAYER, C. \& MIELNICZUK, J. Dinâmica e função da matéria orgânica. In: SANTOS, G.A. \& CAMARGO, F.A.O., eds. Fundamentos da matéria orgânica: Ecossistemas tropicais e subtropicais. Porto Alegre, Gênesis, 1999. p.9-26.

BENITES, V.M.; SCHAEFER, C.E.R.G.; MENDONÇA, E.S. \& MARTIN NETO, L. Caracterização da matéria orgânica e micromorfologia de solos sob campos de altitude no Parque Estadual da Serra do Brigadeiro. R. Bras. Ci. Solo, 25:661-674, 2001.

BENITES, V.M.; SCHAEFER, C.E.G.R.; SIMAS, F.N.B. \& SANTOS, H.G. Soils associated with rock outcrops in the Brazilian mountain ranges Mantiqueira and Espinhaço. R. Bras. Bot., 30:569-577, 2007.

BENITES, V.M.; MOUTTA, R.O.; COUTINHO, H.L.C. \& BALIEIRO, F.C. Análise discriminante de solos sob diferentes usos em área de mata atlântica a partir de atributos da matéria orgânica. R. Árvore, 34:685-690, 2010.

CAMPOS, J.R.R.; SILVA, A.C.; VASCONCELLOS, L.L.; SILVA, D.V.; ROMÃO, R.V.; SILVA, E.B. \& GRAZZIOTTI, P.H. Pedochronology and development of peat bog in the environmental protection area Pau-De-Fruta Diamantina, Brazil. R. Bras. Ci. Solo, 34:1965-1975, 2010.

CAMPOS, J.R.R.; SILVA, A.C.; TORRADO, P.V.; VASCONCELOS, L.L.; SILVA, D.V.; ROMÃO, R.R. \& BISPO, F.H.B. Distribuição das substâncias húmicas na Turfeira da APA Pau-de-Fruta em Diamantina, MG. In: CONGRESSO BRASILEIRO DE CIÊNCIA DO SOLO, 32., Fortaleza, 2009. Anais... Fortaleza, Sociedade Brasileira de Ciência do Solo, 2009. CD-ROM 
CANELLAS, L.P.; BERNER, P.G.; SILVA, S.G.; SILVA, M.B. \& SANTOS, G.A. Frações da matéria orgânica em seis solos de uma toposequência no Estado do Rio de Janeiro. Pesq. Agropec. Bras., 35:133-143, 2000.

CANELlAS, L.P.; VELlOSO, A.C.X.; MARCIANO, C.R.; RAMALHO, J.F.G.P.; RUMJANEK, V.M.; RESENDE, C.E. \& SANTOS, G.A. Propriedades químicas de um Cambissolo cultivado com cana-de-açúcar, com preservação do palhiço e adição de vinhaça por longo tempo. R. Bras. Ci. Solo, 27:935-944, 2003.

CANELLAS, L.P.; ESPINDOLA, J.A.A.; REZENDE, C.E.; CAMARGO, P.B.; ZANDONADI, D.B.; RUMJANEK, V.M.; GUERRA, J.G.M.; TEIXEIRA, M.G. \& BRAZ FILHO, R. Organic matter quality in a soil cultivated with perennial herbaceous legumes. Sci. Agric., 61:53-61, 2004.

CANELLAS, L.P. \& FAÇANHA, A.R. Chemical nature of soil humified fractions and their bioactivity. Pesq. Agropec. Bras., 39:233-240, 2004.

CANELlAS, L.P. \& SANTOS, G.A. Humosfera: Tratado preliminar sobre a química das substâncias húmicas. Campos dos Goytacazes, 2005. 345p. Disponível: <UENF: http://www.uenf.br/Uenf/Pages/CCTA/Lsol/>. Acesso em: 19 abril de 2012.

CASTRO, G.C. Carbono orgânico nas frações granulométricas e húmicas em solos de diferentes texturas sob floresta da região Noroeste Matogrossense. Cuiabá, Universidade Federal de Mato Grosso, 2008. 46p. (Dissertação de Mestrado)

CERRI, C.C. \& VOLKOFF, B. Matéria orgânica de três solos dos campos inundáveis da Ilha de Marajó/PA. R. Bras. Ci. Solo, 12:93-100, 1988.

CONCEIÇÃO, M.; FREIXO, A.A.; ARAÚJO, W.S.; CUNHA, T.J.F.; MARTIN NETO, L.M. \& SAAB, S.C. Caracterização das substâncias húmicas em solos orgânicos do Estado do Rio de Janeiro, sob diversas atividades agrícolas. Rio de Janeiro, 1999. 6p. (Serie Embrapa - Pesquisa em Andamento, 5)

CORDEIRO, F.C. Atributos edáficos em áreas de pastagem plantada em relevo movimentado no noroeste do Estado do Rio de Janeiro. Seropédica, Universidade Federal Rural do Rio de Janeiro, 2006. 103p. (Dissertação de Mestrado)

COELHO, M.S.; MENDONÇA, E.S.; CARDOSO, I.M.; LIMA, P.C.; BARBOSA, I.P. \& FRÁGUAS, L.M. Estoque de carbono e nitrogênio nas frações húmicas de solos sob adubação verde em cultivo orgânico de café. In: CONGRESSO BRASILEIRO DE CIÊNCIA DO SOLO, 32., Fortaleza, 2009. Anais... Fortaleza, Sociedade Brasileira de Ciência do Solo, 2009. CD-ROM

CUNHA, T.J.F.; MACEDO, J.R.; RIBEIRO, L.P.; PALMIERI, F.; FREITAS, P.L. \& AGUIAR, A.C. Impacto do manejo convencional sobre propriedades físicas e substâncias húmicas de solos sob cerrado. Ci. Rural, 31:27-36, 2001.

CUNHA, T.J.F.; MADARI, B.E.; CANELLAS, L.P.; RIBEIRO, L.P.; BENITES, V.M. \& SANTOS, G.A. Soil organic matter and fertility of anthropogenic dark earths (terra preta de índio) in the Brazilian Amazon basin. R. Bras. Ci. Solo, 33:85-93, 2009.
CUNHA, T.J.F.; MADARI, B.E.; BENITES, V.M.; CANELLAS, L.P.; NOVOTNY, E.H.; MOUTTA, R.O.; TROMPOWSKY, P.M. \& SANTOS, G.A. Fracionamento químico da matéria orgânica e características de ácidos húmicos de solos com horizonte A antrópico da Amazônia (Terra Preta). Acta Amaz., 37:91-98, 2007.

EBELING, A.G.; ANJOS, L.H.C.; PEREZ, D.V.; PEREIRA, M.G. \& GOMES, W.F. Atributos químicos, carbono orgânico e substâncias húmicas em Organossolos háplicos de várias regiões do Brasil. R. Bras. Ci. Solo, 35:325-336, 2011.

EMPRESA BRASILEIRADE PESQUISA AGROPECUARIA EMBRAPA. Centro Nacional de Pesquisas de Solos. Sistema brasileiro de classificação de Solos. Rio de Janeiro, Embrapa Solos, 2006. 306 p.

FARIAS, M.O.; LIMA, C.L.R.; SANTOS, D.C.; KUNDE, R.J. \& PILLON, C.N. Estudo da matéria orgânica em um Planossolo Háplico submetido a diferentes sistemas de manejo. Pelotas, Embrapa Clima Temperado, 2010. 36p. (Série Embrapa Boletim de Pesquisa e Desenvolvimento 116)

FERREIRA, D.F. Estatística multivariada. Lavras, Universidade Federal de Lavras, 2011. 676p.

FERREIRA, D.F. Análise Multivariada. Lavras, Universidade Federal de Lavras. Departamento de Exatas, 1996. 400p.

FONTANA, A.; PEREIRA, M.G.; NASCIMENTO, G.B.; ANJOS, L.H.C. \& EBELING, A.G. Matéria orgânica em solos de tabuleiros na região Norte Fluminense-RJ. Flor. Amb., 8:114-119, 2001.

FONTANA, A.; PEREIRA, M.G.; LOSS, A.; CUNHA, T.J.F. \& SALTON, J.C. Atributos de fertilidade e frações húmicas de um Latossolo Vermelho no Cerrado. Pesq. Agropec. Bras., 41:847-853, 2006.

FONTANA, A.; BENITES, V.M.; PEREIRA, M.G. \& ANJOS, L.H.C. Substâncias húmicas como suporte à classificação de solos Brasileiros. R. Bras. Ci. Solo, 32:2073-2080, 2008.

FONTANA, A.; BRITO, R.J.; PEREIRA, M.G.; LOSS, A. \& BENITES, V.M. Caracterização de substâncias húmicas da camada superficial do solo sob diferentes coberturas vegetais. Magistra, 22:48-55, 2010a

FONTANA, A.; PEREIRA, M.G.; ANJOS, L.H.C. \& BENITES, V.M. Quantificação e utilização das frações húmicas como característica diferencial em horizontes diagnósticos de solos brasileiros. R. Bras. Ci. Solo, 34:1241-1257, 2010b.

FONTANA, A.; SILVA, C.F.; PEREIRA, M.G.; LOSS, A.; BRITO. R.J. \& BENITES, V.M. Avaliação dos compartimentos da matéria orgânica em área de Mata Atlântica. Acta Sci. Agron., 33:545-550, 2011.

FREITAS, I.C.V.; SILVA, F.N.; SILVA, R.R.P.S. \& COTTA, A.P. Substâncias húmicas e fúlvicas em diferentes sistemas de uso e manejo do solo em bioma Cerrado. In: CONGRESSO BRASILEIRO DE CIÊNCIA DO SOLO, 32., Fortaleza, 2009. Anais... Fortaleza, Sociedade Brasileira de Ciência do Solo, 2009. CD-ROM

GIÁCOMO, R.G.; PEREIRA, M.G. \& BALIEIRO, F.C. Estoques de carbono e nitrogênio e distribuição das frações húmicas no solo sob diferentes coberturas florestais. R. Bras. Ci. Agron., 3:42-48, 2008. 
GUERRA, J.G.M. \& SANTOS, G.A. Métodos químicos e físicos. In: SANTOS, G.A. \& CAMARGO, F.A.O., eds. Fundamentos da matéria orgânica do solo ecossistemas tropicais e subtropicais. Porto Alegre, Gênesis, 1999. 49p.

HAYES, M.H.B. Humic substances: Progress towards more realistic concepts of structures. In: DAVIES, G. \& GHABBOUR, E.A., eds. Humic substances: Structures, properties and uses. Cornwall, MPG Books, 1998. p.1-27.

OLIVEIRA JR, M.M. \& MELO, W.J. Alterações na matéria orgânica e na biomassa microbiana em solo de mata natural submetido a diferentes manejos. Pesq. Agropec. Bras., 35:1177-1182, 2000.

MARCHIORI JR, O.A.C.; SILVA, C.A.; CURI, N.; GUILHERME, L.R.G. \& RANGEL, O.J.P. Indicadores químicos de qualidade da matéria orgânica de solo da sub-bacia do Rio das Mortes sob manejos diferenciais de cafeeiro. Quím. Nova, 31:1733-1737, 2008.

LIMA, H.N. Gênese, química e micromorfologia de solos da Amazônia Ocidental. Viçosa, MG, Universidade Federal de Viçosa, 2001. 176p. (Tese de Doutorado)

LIMA, P.C. \& BEZERRA NETO, E.B. Carbono orgânico total e substâncias húmicas em Latossolo sob diferentes manejos. In: CONGRESSO BRASILEIRO DE CIÊNCIA DO SOLO, 32., Fortaleza, 2009. Anais... Fortaleza, Sociedade Brasileira de Ciência do Solo, 2009. CD-ROM

LEITE, L.F.C.; MENDONÇA, E.S.; NEVES, J.C.L.; MACHADO, P.L.O. \& GALVÃO, J.C.C. Estoques totais de carbono orgânico e seus compartimentos em Argissolo sob floresta e sob milho cultivado com adubação mineral e orgânica. R. Bras. Ci. Solo, 27:821-832, 2003.

LONGO, R.M. \& ESPÍNDOLA, C.R. Carbono orgânico, nitrogênio total e substâncias húmicas do sob influência da introdução de pastagens (Brachiaria sp) em áreas de Cerrado e floresta Amazônica. R. Bras. Ci. Solo, 24:723-729, 2000.

LOSS, A.; PEREIRA, M.G. \& BRITO, R.J. Distribuição das substâncias húmicas em solos de tabuleiros sob diferentes coberturas vegetais. R. Univ. Rural Série Ci. Vida, 26:5769, 2006.

LOSS, A.; TEIXEIRA, M.B.; OLIVEIRA, A.B.; LIMA, F.M.; CRUZ, R.B.; FONTANA, A. \& PEREIRA, M.G. Fracionamento químico da matéria orgânica do solo em áreas sob diferentes coberturas vegetais e manejo agroecológico. R. Bras. Agroecol., 2:1389-1393, 2007.

LOSS, A.; PEREIRA, M.G.; SCHULTZ, N.; ANJOS, L.H. C. \& SILVA, E.M.R. Substâncias húmicas do solo sob manejo agrícola em diferentes sistemas de produção orgânico. In: FERTBIO, Londrina, 2008. Anais... Londrina, 2008. CD-ROM

LOSS, A.; PEREIRA, M.G.; FERREIRA, E.P.; SANTOS, L.L. \& FERRAZ JÚNIOR, A.S.L. Carbono das frações húmicas de Argissolo Vermelho-Amarelo sob sistemas de cultivo em aléias, São Luis, MA. R. Bras. Ci. Solo, 4:2455-2459, 2009.

LOSS, A.; PEREIRA, M.G.; SCHULTZ, N.; ANJOS. L.H.C. \& SILVA, E.M.R. Quantificação do carbono das substâncias húmicas em diferentes sistemas de uso do solo e épocas de avaliação. Bragantia, 69:913-922, 2010.
MACHADO, D.L.; PEREIRA, M.G.; GIÁCOMO, R.G. \& SANTOS, L.L. Fertilidade do solo e caracterização da matéria orgânica em áreas sob Latossolo Vermelho na Estação Ecológica de Pirapitinga (MG). In: CONGRESSO BRASILEIRO DE CIÊNCIA DO SOLO, 32, Fortaleza, 2009. Anais... Fortaleza, Sociedade Brasileira de Ciência do Solo, 2009. CD-ROM

MACHADO, D.L.; PEREIRA, M.G.; CORREIA, M.E.F.; SANTOS, L.L.; DINIZ, A.R. \& MENEZES, C.E.G. Caracterização das frações físicas e químicas da matéria orgânica do solo em diferentes estádios sucessionais, Brasil. In: FERTBIO, Guarapari, 2010. Anais... Guarapari, 2010. CD-ROM

MELO, V.F. Solos e indicadores de uso agrícola em Roraima: Áreas Indígena Maloca Flechal e de colonização do Apiaú. Viçosa, MG, Universidade Federal de Viçosa, 2002. 145p. (Tese de Doutorado)

MELO, V.F. \& SCHAEFER, C.E.G.R. Matéria orgânica em solos desenvolvidos de rochas máficas no Nordeste de Roraima. Acta Amaz., 39:53- 60, 2009.

MENEZES, C.E.G. Integridade de paisagem, manejo e atributos do solo no médio Vale do Paraíba do Sul. Pinheiral, Universidade Federal Rural do Rio de Janeiro, 2008a. 175p. (Tese de Doutorado).

MENEZES, F.P. Substâncias húmicas em solos de diferentes feições geomorfológicas no rebordo do Planalto do Rio Grande do Sul. Santa Maria, Universidade Federal de Santa Maria, 2008b. 112p. (Dissertação de Mestrado)

MIRANDA, C.C.; CANELLAS, L.P. \& NASCIMENTO, M.T. Caracterização da matéria orgânica do solo em fragmentos de mata atlântica e em plantios abandonados de eucalipto. R. Bras. Ci. Solo, 31:905-916, 2007.

MORAES, L.F.D.; CAMPELLO, E.F.C., PEREIRA, M.G. \& LOSS, A. Características do solo na restauração de áreas degradadas na reserva biológica de Poço das Antas, RJ. Ci. Flor., 18:193-206, 2008.

MOREIRA, A. Fertilidade, matéria orgânica e substâncias húmicas em solos antropogênicos da Amazônia Ocidental. Bragantia, 66:307-315, 2007.

MOITA NETO, J.M. Estatística multivariada. Fundação de Amparo à Pesquisa do Estado do Piauí. 2006. Disponível em: <http://www.fapepi.pi.gov.br/novafapepi/ciencia/ documentos/multivariada.PDF $>$. Acesso em: $15 \mathrm{dez} .2011$.

NASCIMENTO, V.N.; ALMENDROS, G. \& FERNANDES, F.M. Evolution patterns of the soil organic matter in some agricultural systems in the Brazilian "Cerrado"region. Eur. J. Soil. Biol., 29:177-182, 1993.

PARTELLI, F.L.; BUSATO, J.G.; VIEIRA, H.D.; VIANA, A.P. \& CANELLAS, L.P. Qualidade da matéria orgânica e distribuição do fósforo no solo de lavouras orgânicas de café Conilon. Ci. Rural, 39:2065-2071, 2009.

PORTUGAL, A.F.; JUCKSCH, I.; SCHAEFER, C.E.G.R. \& WENDLING, B. Determinação de estoques totais de carbono e nitrogênio e suas frações em sistemas agrícolas implantados em Argissolo Vermelho-Amarelo. R. Bras. Ci. Solo, 32:2091-2100, 2008. 
ROSA, C.M.; CASTILHOS, R.M.V.; DICK, D.P.; PAULETTO, E.A. \& GOMES, A.S. Teor e qualidade de substâncias húmicas de Planossolo sob diferentes sistemas de cultivo. Ci. Rural, 38:1589-1595, 2008.

SANTANA, G.S. Compartimento químico e físico da matéria orgânica de Latossolo em sistemas de manejo e pastagens dos Campos de Cima da Serra, RS. Porto Alegre, Universidade Federal do Rio Grande do Sul, 2010. 81p. (Dissertação de Mestrado)

SANTOS, L.L.; LOSS, A.; PEREIRA, M.G.; FERREIRA, E.P. \& FERRAZ JÚNIOR, A.S.L. Carbono das frações húmicas de Argissolo Vermelho-Amarelo sob sistemas de cultivo em Aléias, São Luis, MA. R. Bras. Agron., 4:2455-2459, 2009a.

SANTOS, L.L.; LOSS, A.; PEREIRA, M.G.; BERNINI, T.A.; ANJOS, L.H.C.; MORAES, A.G.L. \& WADT, P.G.S. Distribuição das substâncias húmicas de horizontes superficiais em topossequências sob floresta no Acre. In: FERTBIO, Londrina, 2008. Anais... Londrina, 2008. CD-ROM

SANTOS, L.L.; MACHADO, D.L.; PEREIRA, M.G. \& GIÁCOMO, R.G. Fertilidade do solo e caracterização da matéria orgânica em áreas sob Cambissolo Háplico na Estação Ecológica de Pirapitinga (MG). In: CONGRESSO BRASILEIRO DE CIÊNCIA DO SOLO, 32, Fortaleza, 2009. Anais... Fortaleza, Sociedade Brasileira de Ciência do Solo, 2009b. CD-ROM

SANTOS, L.L.; LOSS, A.; PEREIRA, M.G.; PERIN, A. \& ANJOS, L.H.C. Carbono das substâncias húmicas em Latossolo sob sistema plantio direto com integração lavoura-pecuária. In: FERTBIO, Guarapari, 2010. Anais... Guarapari, 2010. CD-ROM

SCHAEFER, C.E.R.; SILVA, D.D.; PAIVA, K.W.N.; PRUSKI, F.F.; ALBUQUERQUE FILHO, M.R. \& ALBUQUERQUE, M.A. Perdas de solo, nutrientes, matéria orgânica e efeitos microestruturais em Argissolo Vermelho-Amarelo sob chuva simulada. Pesq. Agropec. Bras., 37:669-678, 2002.

SCHIAVO, J.A.; CANELlAS, L.P. \& MARTINS, M.A. Revegetação de cava de extração de argila com Acacia mangium. I - atributos químicos do solo, ácidos fúlvicos e húmicos. R. Bras. Ci. Solo, 31:1153-1162, 2007.

SCHIAVO, J.A.; BUSATO, J.G.; MARTINS, M.A. \& CANELLAS, L.P. Recovery of degraded areas revegeted with Acacia mangium and Eucalyptus with special reference to organic matter humification. Sci. Agric., 66:353-360, 2009.

SCHMIDT, M.W.I.; TORN, M.S.; ABIVEN, S.; DITTMAR, T.; GUGGENBERGER, G.; JANSSENS, I.A.; KLEBER, M.; KOGEL-KNABNER, I.; LEHMANN, J.; MANNING, D.A.C.; NANNIPIERI, P.; RASSE, D.P.; WEINER, S. \& TRUMBORE, S.E. Persistence of soil organic matter as an ecosystem property. Nature, 478:49-56, 2011.

STEVENSON, F.J. Humus chemistry: Genesis, composition, reactions. 2.ed. New York, Wiley, 1994. 512p.
SILVA, A.C.; HORÁK, I.; TORRADO, P.V.; CORTIZAS, A.M.; RACEDO, J.R. \& CAMPOS, J.R.R.C. Turfeiras da Serra do Espinhaço Meridional - MG II - Influência da drenagem na composição elementar e substâncias húmicas. R. Bras. Ci. Solo, 33:1399-1408, 2009.

SILVA, C.A.; ANDERSON, S.J. \& GUILHERME, L.R.G. Uso da cromatografia de exclusão por tamanho na caracterização de substâncias húmicas de Latossolo Vermelho-Escuro sob efeito da calagem. R. Bras. Ci. Solo, 24:495-503, 2000.

SILVA, R.C.; ANJOS, L.H.C.; PEREIRA, M.G. \& MENEZES, C.E.G. Quantificação do carbono das substâncias húmicas em solos da região do Médio Vale do Paraíba do Sul, Pinheiral, RJ. In: FERTBIO, Guarapari, 2010. Anais... Guarapari, 2010. CD-ROM

SILVA, S.C. \& SBRISSIA, A.F. Análise de componentes principais entre características morfogênicas e estruturais em capim-marandu sob lotação contínua. Ci. Rural, 40:690-693, 2010.

SOARES, E.M.B. Frações da matéria orgânica e composição molecular de substâncias húmicas de solos sob cultivo de eucalipto em biomas distintos. Viçosa, MG, Universidade Federal de Viçosa, 2009. 136p. (Tese de Doutorado)

ROCHA, J.C. \& ROSA, A.H. Substâncias húmicas aquáticas interações com espécies metálicas. São Paulo, UNESP, 2003. 110p.

TEIXEIRA, R.S.; SILVA, I.R.; SOARES, E.M.B.; FIALHO, R.C.; BARROS, N.F. \& NOVAIS, R.F. Impacto do cultivo do eucalipto nas substâncias húmicas em solos de texturas distintas no leste do Rio Grande do Sul. In: FERTBIO, Guarapari, 2010. Anais... Guarapari, 2010. CD-ROM

VALLADARES, G.S.; BENITES, V.M.; PEREIRA, M.G.; ANJOS, L.H.C. \& EBELING, A.G. Proposta para classificação de Organossolos em níveis inferiores com base nas frações húmicas. Campinas, Embrapa Monitoramento por Satélite, 2003. 35p. (Boletim de Pesquisa e Desenvolvimento, 2)

VILLANI, F.T.; RIBEIRO, G.A.A.; ALFAIA, S.S. \& VILLANI, E. Fracionamento químico e físico da matéria orgânica e estoque de carbono e nitrogênio em solos de sistemas agroflorestais e outras coberturas vegetais em comunidades indígenas no Alto Solimões-Amazonas. In: FERTBIO, Guarapari, 2010. Anais... Guarapari, 2010. CD-ROM

ZECH, W.; SENESI, N.; GUGGENBERGER, G.; KAISER, K.; LEHMANN, J.; MIAN, T.M.; MILTNER, A. \& SCHROTH, G. Factors controlling humification and mineralization of soil organic matter in the tropics. Geoderma, 79:117$161,1997$.

ZINN, Y.L.; LAL, R.; BIGHAM, J.M. \& RESCK, D.V.S. Edaphic controls on soil organic carbon retention in the Brazilian Cerrado: Soil texture and mineralogy. Soil Sci. Soc. Am. J., 71:1204-1214, 2007. 